GA-A15573

UC-77

\title{
界 \\ กำ \\ INCREMENTAL STRESS-STRAIN LAW FOR GRAPHITE UNDER MULTIAXIAL LOADINGS
}

\author{
by \\ FU-KONG TZUNG
}

Prepared under

Contract DE-AT03-76ET35300

for the San Francisco Operations Office

Department of Energy

DATE PUBLISHED: NOVEMBER 1979

\section{GENERAL ATOMIC COMPANY}




\section{DISCLAIMER}

This report was prepared as an account of work sponsored by an agency of the United States Government. Neither the United States Government nor any agency Thereof, nor any of their employees, makes any warranty, express or implied, or assumes any legal liability or responsibility for the accuracy, completeness, or usefulness of any information, apparatus, product, or process disclosed, or represents that its use would not infringe privately owned rights. Reference herein to any specific commercial product, process, or service by trade name, trademark, manufacturer, or otherwise does not necessarily constitute or imply its endorsement, recommendation, or favoring by the United States Government or any agency thereof. The views and opinions of authors expressed herein do not necessarily state or reflect those of the United States Government or any agency thereof. 


\section{DISCLAIMER}

Portions of this document may be illegible in electronic image products. Images are produced from the best available original document. 


\title{
NOTICE
}

This report was prepared as an account of work sponsored by the United States Government. Neither the United States nor the United States Department of Energy, nor any of their employees, nor any of their contractors, subcontractors, or their employees, makes any warranty, express or implied, or assumes any legal liability or responsibility for the accuracy, completeness or usefulness of any information, apparatus, product or process disclosed, or represents that its use would not infringe privately owned rights.

\author{
Printed in the United States of America \\ Available from \\ National Technical Information Service \\ U.S. Department of Commerce \\ 5285 Port Royal Road \\ Springfield, Virginia 22161 \\ Price: Printed Copy $\$ 4.50$; Microfiche $\$ 3.00$
}


GA-A15573

UC-77

\title{
INCREMENTAL STRESS-STRAIN LAW FOR GRAPHITE UNDER MULTIAXIAL LOADINGS
}

\author{
by \\ FU-KONG TZUNG
}

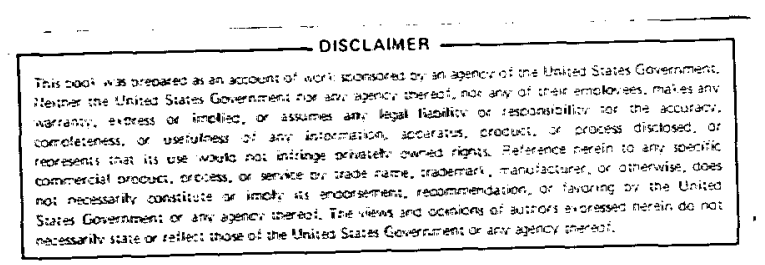

Prepared under

Contract DE-AT03-76ET35300

for the San Francisco Operations Office

Department of Energy

\author{
GENERAL ATOMIC PROJECT 6400 \\ DATE PUBLISHED: NOVEMBER 1979
}

\section{GENERAL ATOMIC COMPANY}




\section{ABSTRACT}

An incremental stress-strain law for describing the nonlinear, compressible and asymmetric behavior of graphite under tension and compression as well as complex loadings is derived based on a dry friction model in the theory of plasticity. Stress-strain relations are defined by longitudinallateral strain measurements for specimens under uniaxial tension-compression. Agreements with experimentally determined curves from biaxial loading experiments are shown. Agreements in finite element computations using the present model with strain measurements for diametral compression and 4point bend tests of graphite are also obtained. 
Page

SUMMARY . . . . . . . . . . . . . . . . . . . . 1

INTRODUCTION .......................... . . . . . 2

DERIVATION OF AN INCREMENTAL STRESS-STRAIN RELATION . . . . . . . 3

APPLICATION OF THE THEORY . . . . . . . . . . . . . . . 6

BIAXIAL LOADING COMPARISONS . . . . . . . . . . . . • 7

CONCLUSION . . . . . . . . . . . . . . . . . . 25

ACKNOWLEDGEMENTS •.................... . . 26

REFERENCES .......................... . . 27 


\section{SUMMARY}

An incremental stress-strain law to describe the behavior of graphite under complex loadings has been derived and its predictions compared to a limited set of experimental data. The comparison is quite good and suggests that this theoretical approach should be pursued further.

The derivation is similar to that of the classical theory of plasticity inasmuch as a loading function and a hardening rule are established and in that kinematic hardening can be used to model hysteresis effects. It differs, however, in that the hardening function is determined by only a portion of, not the entire, loading function. This refinement, which is mathematically rigorous, adds the flexibility needed to treat the nonlinear, compressible and asymetric deformation behavior of graphite under either tension or compression.

The theory has been tested by comparing its predictions to existing experimental data from diametral compression tests and 4-point bend tests for H-327 graphite. Material constants were determined from uniaxial tensile tests and then applied to the analysis of the experiments. The agreement with experimentally determined stress-strain curves from biaxial loading experiments was good and, as would be expected, superior to that achievable with a linear elastic model. Also, failure stresses were better predicted, i.e. they were closer to the measured ultimate tensile strength. Although more experimental data are needed before any firm conclusion can be drawn, it does appear that this theory might well provide a substantially improved framework for design analysis of graphite components. 


\section{INTRODUCTION}

Since graphite is used extensively in the core and reactor internals of an HTGR, it is important that analytical models be available to predict the stress levels that result from the multi-axial thermal and mechanical loadings to which the graphite components are subjected. Current design techniques make use of a linear elastic model to describe the behavior of graphite. Although this approach, when coupled with suitable design conservatism, is adequate, past comparisons of its predictions with experimental data have not been wholly satisfactory. This report describes a study undertaken to see if a more sophisticated model of the behavior of graphite could improve the situation.

Classical plasticity assumes a yield stress and an incompressible plastic deformation - two assumptions that are inconsistent with experimental observations that the deformation of graphite is essentially nonlinear and compressible from zero stress to failure stress as well as asymmetric in tension and compression. Therefore, this theory is not likely to provide satisfactory results for graphite.

Deformation type theories, such as those of Weng [2], Jones and Nelson [3] and Batdorf [4], have been proposed. Since these theories define strain as a unique function of stress, they are unsuitable for general design analyses which must model the hysteresis effects that will occur during operational cycling in a reactor.

Rate type theories were proposed by Greenstreet, Yahr, and Valanchovic [5], Greenstreet and Philips [6], and Chang, Reich and Suzuki [7]. In [5], the theory is applicable only in the tension quadrant; [6] only addresses uniaxial or proportional loadings; and [7] did not define the relationship among incremental strain, stress and plastic strain explicitly enough to permit practical applications in the absence of an extensive experimental program. 
On the basis of this review, an incremental strain law based upon a dry friction model was formulated. The derivation of this model and the results of its application to several experiments are described below.

\section{DERIVATION OF AN INCREMENTAL STRESS-STRAIN RELATION}

To establish a material model to describe the response of graphite under stress, consider the dry friction model shown in Figure 1 . Just prior to motion, the equality

$$
+\mu \vec{N}=\mu \vec{W} \text {, }
$$

must be satisfied.

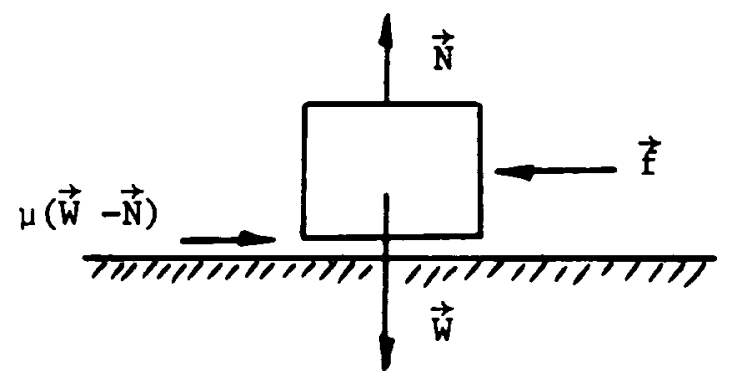

Fig. 1. Dry Friction Mode1

The direction of the motion is related to the shear force $t$ and independent of the normal force $\vec{N}$. To generalize this concept for a relation between the stress $\sigma_{i j}$ and the inelastic strain tensors $\varepsilon_{i j}^{p}(i, j=1,2,3)$, we define a loading function

$$
F\left(\sigma_{i j}, \varepsilon_{1 j}^{p}, k\right) \equiv f\left(\sigma_{i j}\right)+\mu N\left(\sigma_{i j}\right)-k\left(\varepsilon_{i j}^{p}\right)
$$

and a hardening rule

$$
d \varepsilon_{1 j}^{p}=\frac{\partial f}{\partial \sigma_{1 j}} d \lambda
$$


The hardening rule defined above differs from the flow rule of classical plasticity theory by using $\partial f / \partial \sigma_{1 j}$ instead of $\partial F / \partial \sigma_{1 j}$ in Eq. (3). This is permissible for the same reason that the direction of the block motion in Fig. 1 depends on the force but not on the force $\vec{N}$. Thermodynamic restrictions are clearly satisfied. Indeed mathematic proof of this statement can be found in [8] for a more general case. Since the cycling of graphite between zero stress and preload stress does not change the stress-strain hysteresis appreciably [1], the loading function has been assumed to be a function of the state variable $\sigma_{i j}$ and $\varepsilon_{i j}^{p}$ in Eq. (2). A simple expression for $f\left(\sigma_{i j}\right), N\left(\sigma_{i j}\right)$ and $k\left(\varepsilon_{i j}^{p}\right)$ that enables one to treat the different volume changes and the asymmetric behavior of graphite in tension and compression is given in the following:

$$
\begin{aligned}
& f\left(\sigma_{i j}\right)=B\left\{C_{i j k \ell}^{*} \sigma_{i j} \sigma_{k \ell}+\frac{1}{2} \gamma_{i j} \sigma_{i j}\left[\gamma_{k \ell} \sigma_{k \ell}+\left|\gamma_{k \ell} \sigma_{k \ell}\right|\right]\right\}^{n / 2}, \\
& N\left(\sigma_{i j}\right)=B \sigma_{i j}\left|\sigma_{j j}\right|^{n-1}, \quad n>0, \\
& k\left(\varepsilon_{i j}^{p}\right)=\left(\varepsilon_{i j}^{p} \varepsilon_{i j}^{p}\right)^{1 / 2}
\end{aligned}
$$

where $i, j, k, l=1,2,3$, and a repeated subscript indicates summation. 
The constants $C_{i j k \ell}^{*}$ must satisfy the condition that $F\left(\sigma_{i j}, \varepsilon_{i j}^{p}, k\right) \geq 0$ for all $\sigma_{i j}$ and $\varepsilon_{i j}^{p}$, and $\left|\gamma_{k \ell} \sigma_{k \ell}\right|$ denotes the absolute value of the argument. The value of $\mathrm{d} \lambda$ is obtained here as follows:

$$
\begin{aligned}
\mathrm{d} \lambda & =\frac{\partial \mathrm{F}}{\partial \sigma_{i j}} \mathrm{~d} \sigma_{i j} / \frac{\partial f}{\partial \sigma_{k \ell}} \frac{\partial \mathrm{k}}{\partial \varepsilon_{k \ell}^{\mathrm{p}}} \text {, for } \mathrm{F}=0 \text { and } \frac{\partial F}{\partial \sigma_{i j}} \mathrm{~d} \sigma_{1 j} \geq 0 \\
& =0 \text {, for } \frac{\partial \mathrm{F}}{\partial \sigma_{i j}} \mathrm{~d} \sigma_{i j}<0 \text { or } F<0 .
\end{aligned}
$$

For monotonic proportional loadings, the inelastic incremental strain components $\varepsilon_{i j}^{p}$ defined by (2), (3) and (4) are also proportional. The total plastic strain component $\varepsilon_{1 j}^{\mathrm{p}}$ can therefore be obtained by an integration of (3),

$$
\varepsilon_{i j}^{p}=(f+\mu N) \frac{\partial f}{\partial \sigma_{i j}} /\left(\frac{\partial f}{\partial \sigma_{k \ell}} \frac{\partial f}{\partial \sigma_{k \ell}}\right)^{1 / 2} .
$$

The total strain components $\varepsilon_{1 f}$ are therefore related to the stress components $\sigma_{i j}$ as,

$$
\varepsilon_{1 j}=C_{i j k \ell} \sigma_{k \ell}+\varepsilon_{i j}^{p}
$$

where $C_{i j k \ell}$ are the elastic compliances.

To approximate the hysteresis behavior of graphite under cyclic loading, Prager's kinematic hardening rule [9] can be used, 1.e.,

$$
f \equiv f\left(\sigma_{1 j}-c \varepsilon_{1 j}^{p}\right)
$$

replaces $f \equiv f\left(\sigma_{i j}\right)$ in (2) and (4). Although the precise description for the hysteresis, see [6], may not be attainable, the present hardening rule offers a practical and unambiguous treatment for a specimen subjected to complex three-dimensional loadings. 


\section{APPLICATION OF THE THEORY}

To apply the theory, one must experimentally determine values for $c_{i j k \ell}^{*}, c_{i j k \ell}$ and $\gamma_{i j}$.

For graphite, this task can be simplified by making use of the experimental observation that the transverse-to-longitudinal strain ratio remains constant in uniaxial compression tests but decreases with increasing stress in uniaxial tension tests. This suggests the following approximations:

$$
\begin{aligned}
c_{i j k l}^{*} & =\frac{c_{i j k l}}{c_{1111}}, \\
\gamma_{11}=\gamma_{22} & =\sqrt{-c_{1122}^{*}}, \\
r_{33} & =c_{1133}^{*} / \gamma_{11} .
\end{aligned}
$$

With these approximations, Eq. (6), written for uniaxial monotonic loadings, reduces to

$$
\begin{aligned}
\varepsilon_{11}^{\mathrm{p}} & =\left[\left(1+\gamma_{11}^{2}\right)^{\frac{\mathrm{n}}{2}}+\mu\right] \text { B } \sigma_{11}^{\mathrm{n}}, \text { for } \sigma_{11} \text { in tension, } \\
& =[1-\mu] \text { B } \sigma_{11}\left|\sigma_{11}\right|^{\mathrm{n}-1}, \text { for } \sigma_{11} \text { in compression . }
\end{aligned}
$$

This provides a way to use relatively simple uniaxial tests to determine $\mu, B$, and $n$ for subsequent applications. Note that this also establishes the relation that the plastic strain is proportional to the nth power of the stress. 


\section{BIAXIAL LOADING COMPARISONS}

As a first test of the theory, its predictions were compared with experimental data for ATJ graphtte under biaxial loadings [2].

For specimens subjected to monotonic-proportional-biaxial stresses $\sigma_{11}$ and $\sigma_{33}\left(=\mathrm{m} \sigma_{11}\right), \mathrm{Eq} .(7)$ reduces to

$$
\begin{aligned}
& \varepsilon_{11}=A_{1} \sigma_{11}+B_{1} \sigma_{11}\left|\sigma_{11}\right|^{n-1} \\
& \varepsilon_{33}=A_{3} \sigma_{33}+B_{3} \sigma_{33}\left|\sigma_{33}\right|^{n-1},
\end{aligned}
$$

where

$$
\begin{aligned}
& A_{1}=c_{1111}+m C_{1133} \\
& A_{3}=C_{3333}+C_{3311} / m .
\end{aligned}
$$

In the absence of uniaxial test data, the following assumptions were made:

$$
\begin{aligned}
& \mu=0.1 \\
& \mathbf{B}=5.5 \times 10^{-11}(\mathrm{ps} x)^{-\mathrm{n}} \\
& \mathbf{n}=2 .
\end{aligned}
$$

W1th these assumptions, Eqs. (4), (6), (7) and (9) were used to determine values of $B_{1}$ and $B_{3}$ for four different values of $m$, the stress ratio. The comparison with the experimental data is shown in Figures 2 and 3 . The agreement is good throughout the range analyzed and suggests that the theory is indeed applicable to graphite. 


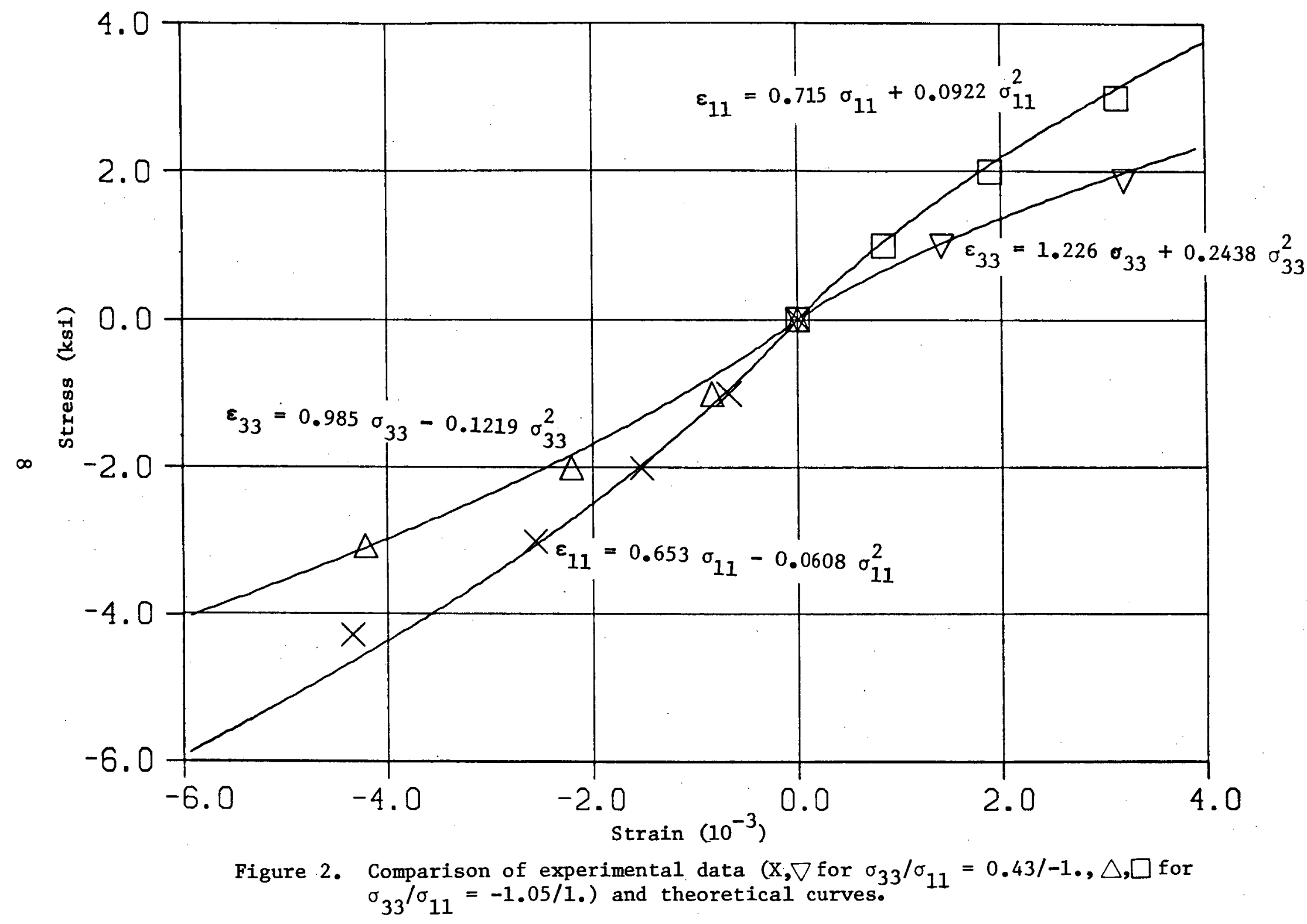




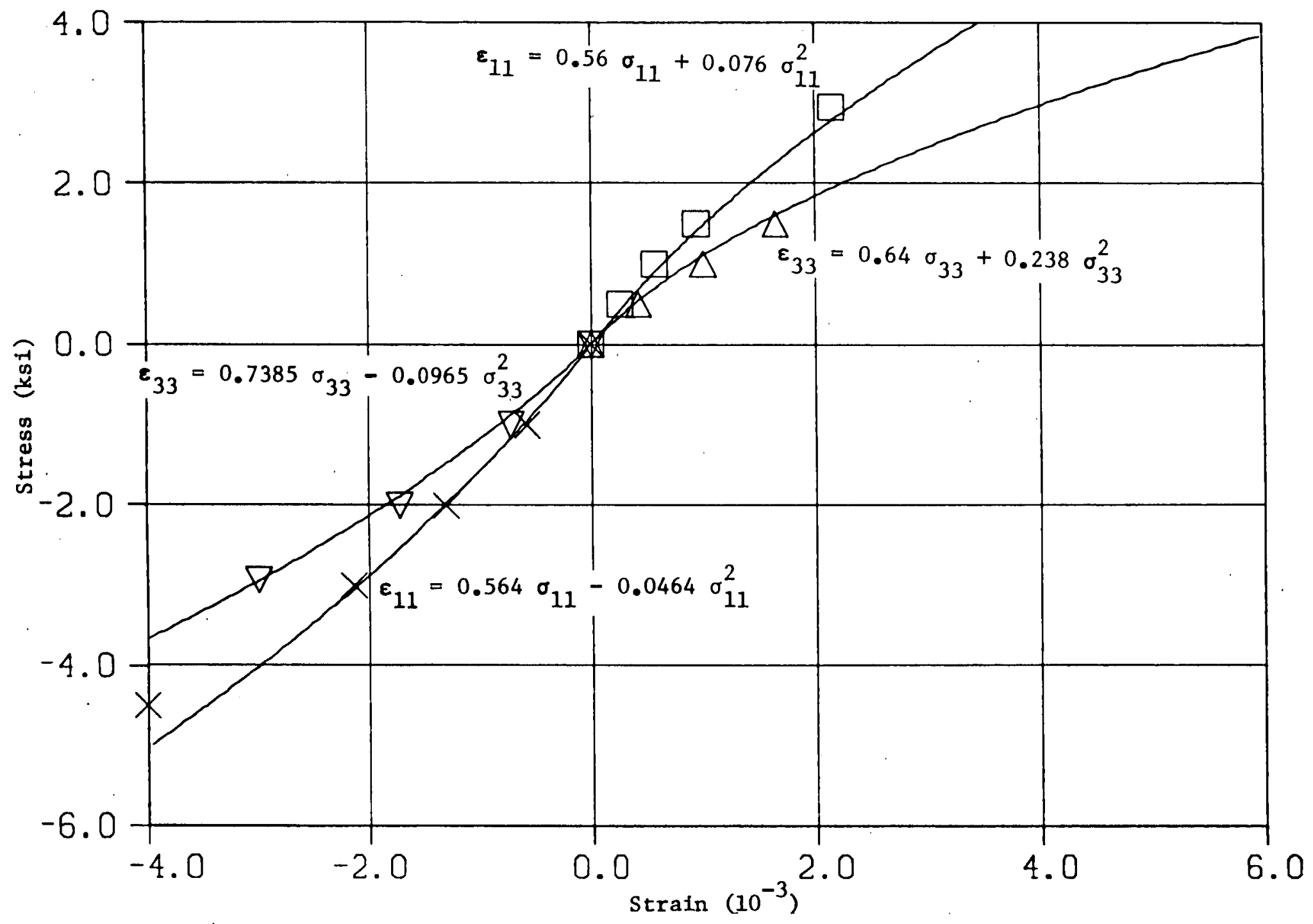

Figure 3. Comparison of experimental data $\left(\square, \triangle\right.$ for $\sigma_{33} / \sigma_{11}=0.5 / 1, \nabla, X$ for $\left.\sigma_{33} / \sigma_{11}=-0.66 /-1_{\bullet}\right)$ and theoretical curves. 
FINITE ELEMENT ANALYSES OF 4-POINT BEND AND DIAMETRAL COMPRESSION TESTS

To provide a tool for further testing, a finite element program, GTEPC-2D [11], was modified to include the incremental stress-strain relationships defined by Eqs. (2)-(6) within a solution scheme based upon the initial stress method [12] for modelling inelastic deformations.

This program was then used to analyze the 4-point bend test and the three diametral compression tests upon $\mathrm{H}-327$ graphite described in [13]. Figures 4 and 5 show the finite element idealizations used in this comparison. The numerical treatment of contact phenomena followed the procedure discussed in [14].

The uniaxial tensile test data shown in Fig. 6 were used to generate the required material constants. From the figure, it is apparent that the data are well fit by the formula

$$
\varepsilon_{11}=1.163 \times 10^{-6} \sigma_{11}+2 \times 10^{-13} \sigma_{11}^{3}
$$

where $\sigma_{11}$ is in psi. This fit, together with the experimental observation that the transverse-to-longitudinal strain ratio observed during the test varied between 0.04 and 0.09 [15], suggests the following approximations

$$
\begin{aligned}
c_{1111}^{*} & =c_{2222}^{*}=1, c_{3333}^{*}=0.4444, \\
c_{1122}^{*} & =c_{2211}^{*}=-0.09, \\
c_{1133}^{*} & =c_{3311}^{*}=c_{2233}^{*}=c_{3322}^{*}=-0.04, \\
\gamma_{11} & =\gamma_{22}=0.3, \gamma_{33}=c_{1133}^{*} / \gamma_{11}, \mu=0, \\
n & =3, \quad B=1.7575 \times 10^{-13}(p s i)^{-n} .
\end{aligned}
$$




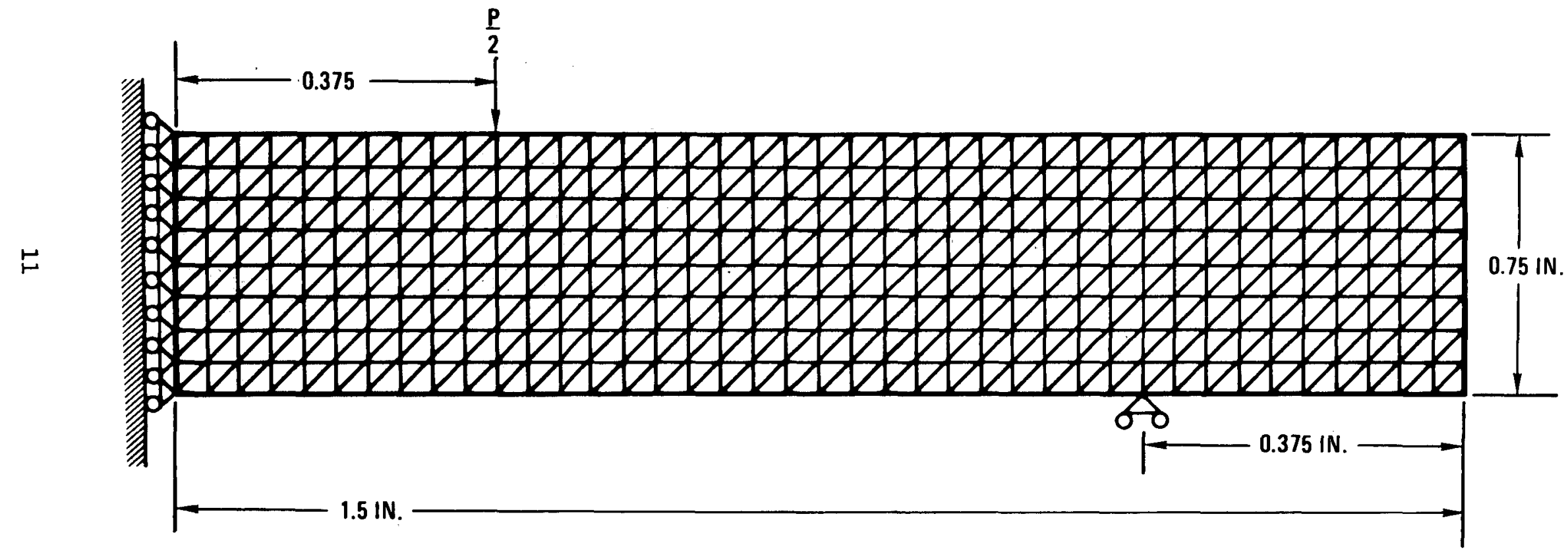

Figure 4. Finite element idealization for 4-point bend of graphite beam. 


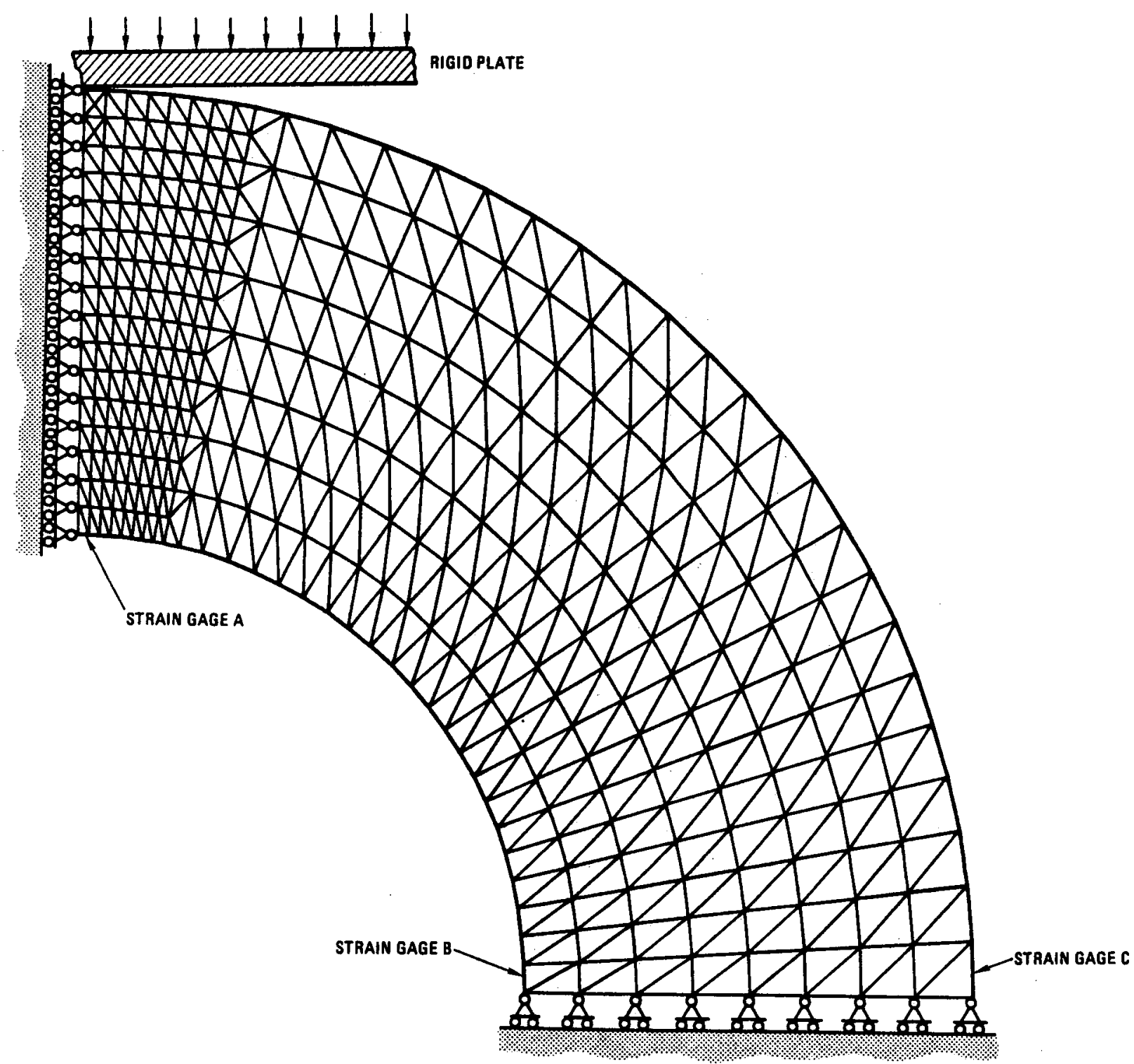

Figure 5. Finite element idealization for diametral compression of graphite ring. 


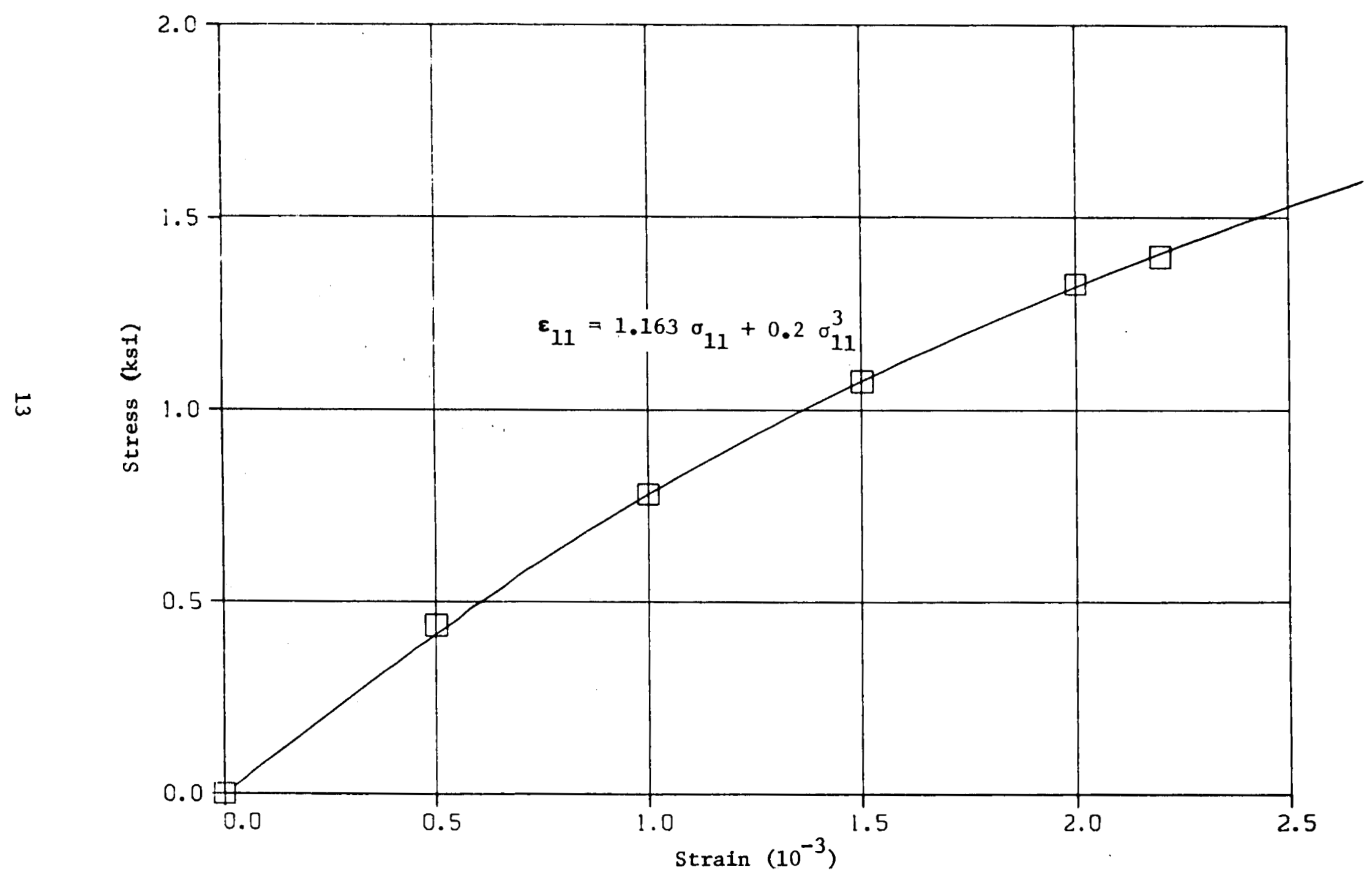

Figure 6. Uniaxial stress-strain relation for H-327 graphite 
Furthermore, since the $C_{i j k l}^{*}$ tensor is proportional to the elastic compliance $\mathrm{C}_{i j k \ell}$, we have

$$
C_{i j k l}=1.163 \times 10^{-6} C_{i j k l}^{*}
$$

which completes the selection of material constants.

It should be noted that since the underlying uniaxial test data were only available up to a maximum stress level of $\sim 1500 \mathrm{psi}$, the results that follow should be interpreted with this implicit limitation in mind.

Figures 7 and 8 show the comparison for the four point bend test. Deflection is well predicted over the entire range of loadings but the strain is overpredicted for higher loadings. Since the stresses at these loadings are outside the data base, it is not clear whether the material data or the theory are at fault or even if the results lie outside the experimental error bounds.

Figures 9, 10, and 11 display the comparison for a compression test on a graphite ring with 2.2 inch ID and a 2.75 inch OD. Here the strain is well predicted over the entire range of loadings but the deflection is underpredicted at the higher loadings. The strain comparisons are especially interesting because they indicate a substantial experimental uncertainty.

Figures 12, 13 and 14 show a similar comparison for a thicker ring the ID is 1.375". The deflection is now well predicted as is the strain.

Table I contains a comparison of the predictions and the measured data at failure. Also included are the maximum tensile stresses predicted by the linear model currently in use. Both models calculate a fallure stress higher than the measured ultimate tensile strength, which is typically $1500 \mathrm{psi}$, but the new model is $\sim 30 \%$ closer to this value. Thus it represents a substantial improvement. 
The last two rows summarize two other comparisons. One is a very thick ring, an I.D. of 0.5 ". Here the agreement is worsened although the new model retains its superiority. The other is an experiment similar to that sumarized in row 2 but which was performed without a strain gage. Note that the failure load is decreased by $215 \%$. This suggests that the presence of a strain gage can alter the experimental results significantly. The predicted results, which were obtained using consistent material property data, are in better agreement than in the cases where a strain gage was used. It appears possible that this might be because this experiment was more homogeneous than the others but there is not enough data to support this statistically. 


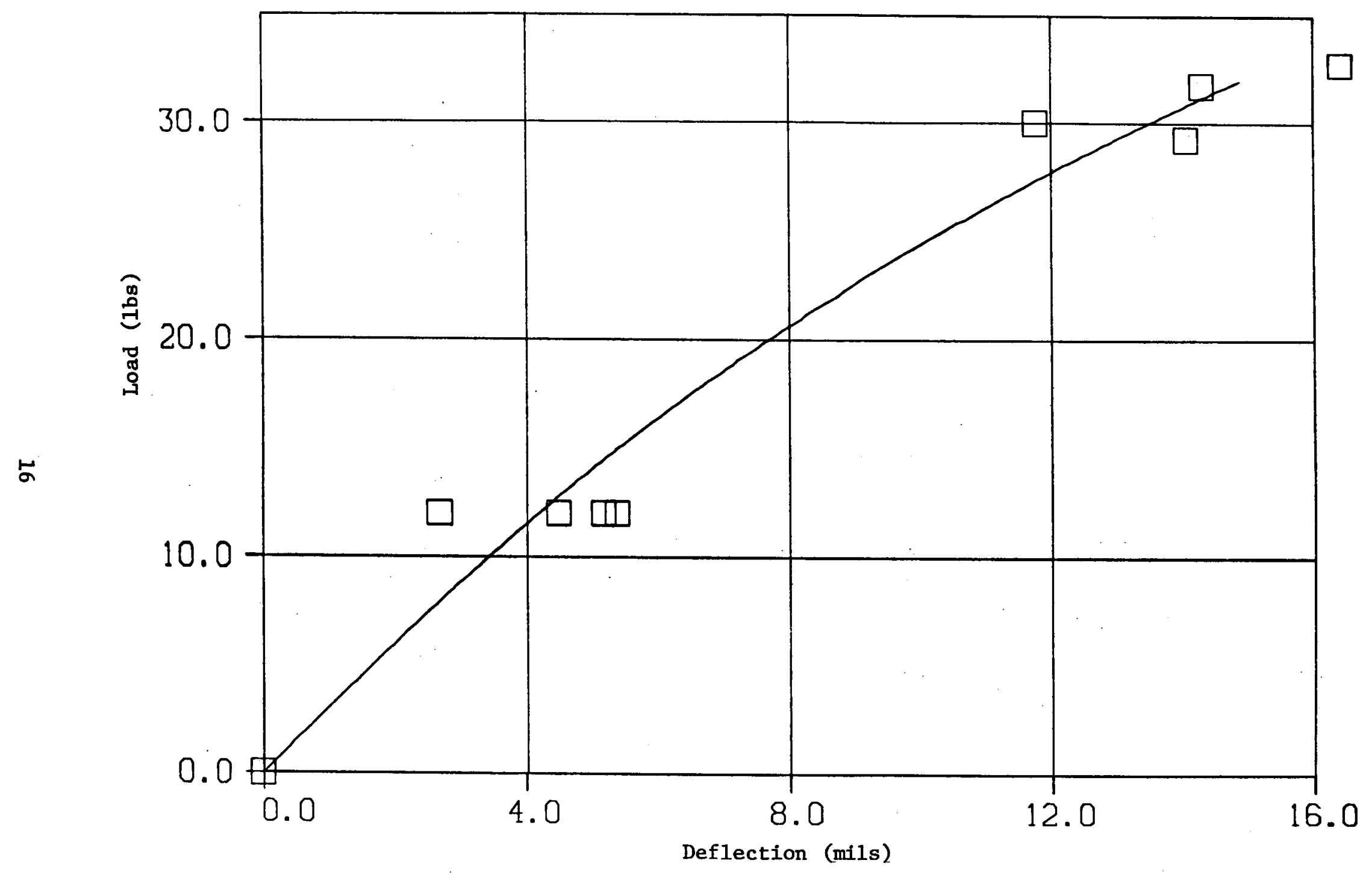

Figure 7. Comparison of deflection measurements ( $\square$ ) and predictions for H-327 graphite under 4-point bend. 


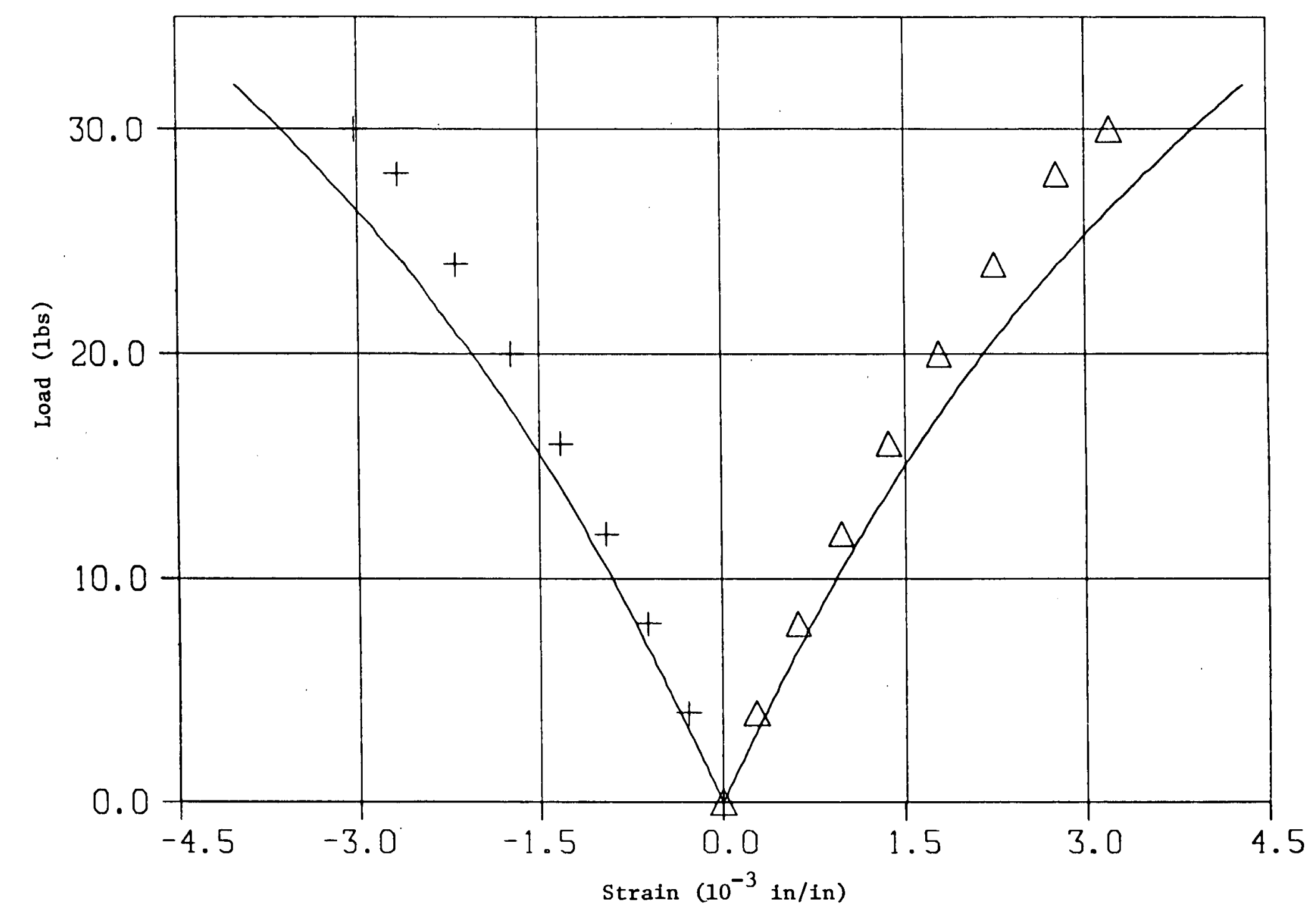

Figure 8. Comparison of strain measurements on the top $(+)$ and the bottom $(\triangle)$ surfaces at the mid-span of the beam with predictions for $\mathrm{H}-327$ graphite under 4-point bend. 


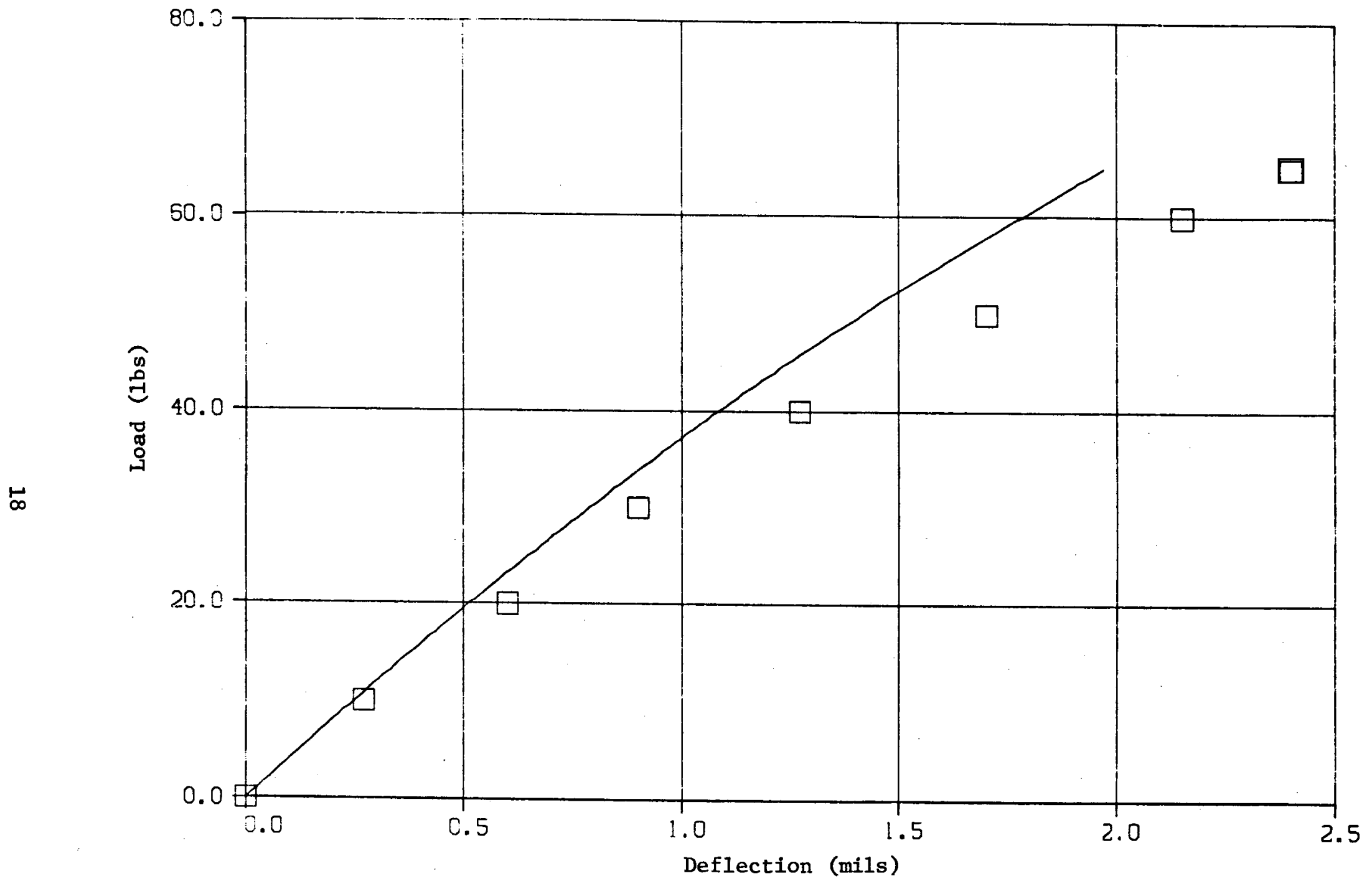

Figure 9. Comparison of deflection measurements ( $\square$ ) and predictions for graphite ring of 2.2 inches inside and 2.75 inches outside diameters under diametral compression. 


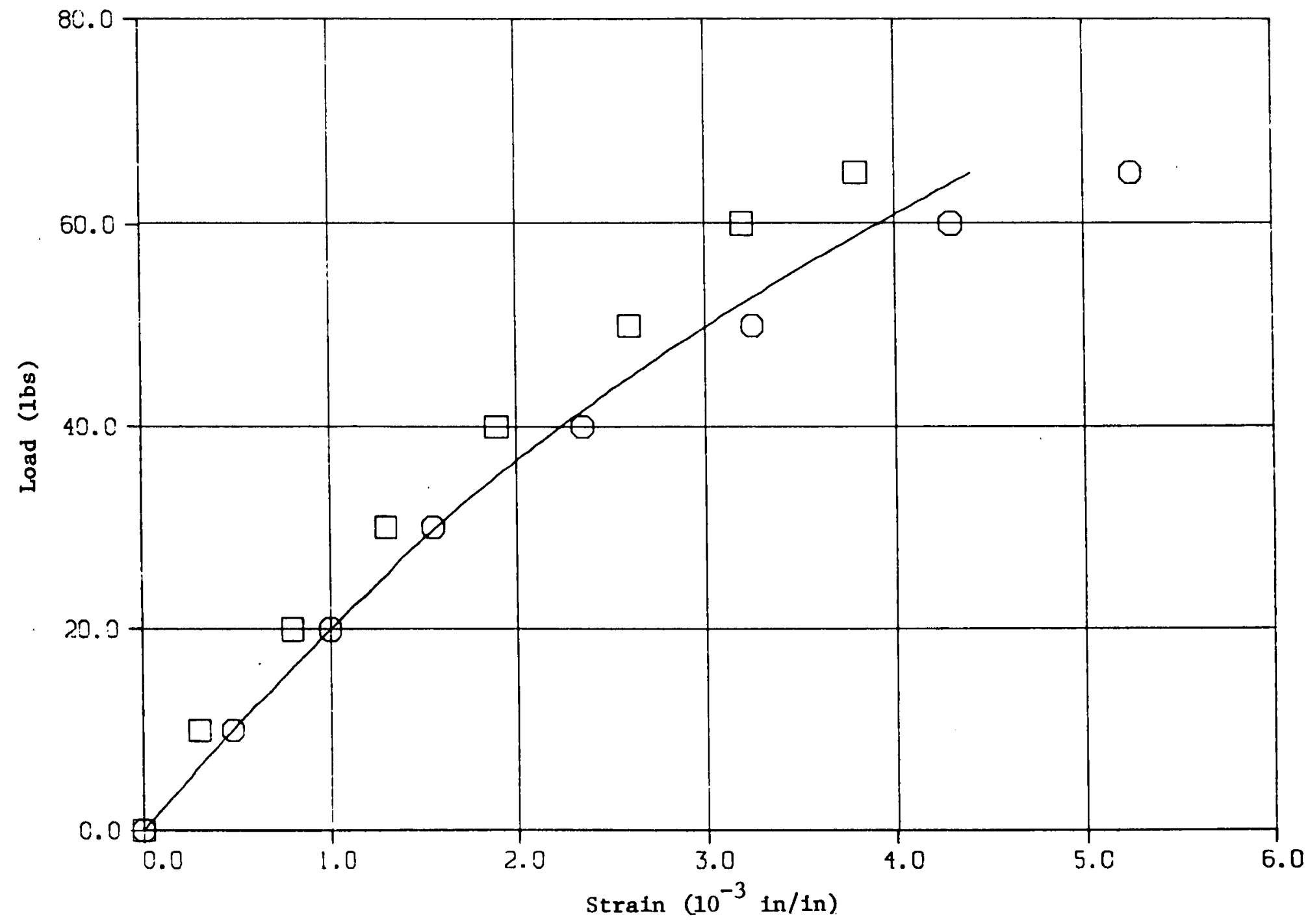

Figure 10. Comparison of strain measurements $(\square, \bigcirc)$ at location $A$ and predictions for graphite ring of 2.2 inches inside diameter and 2.75 inches outside diameter under diametral compression. 


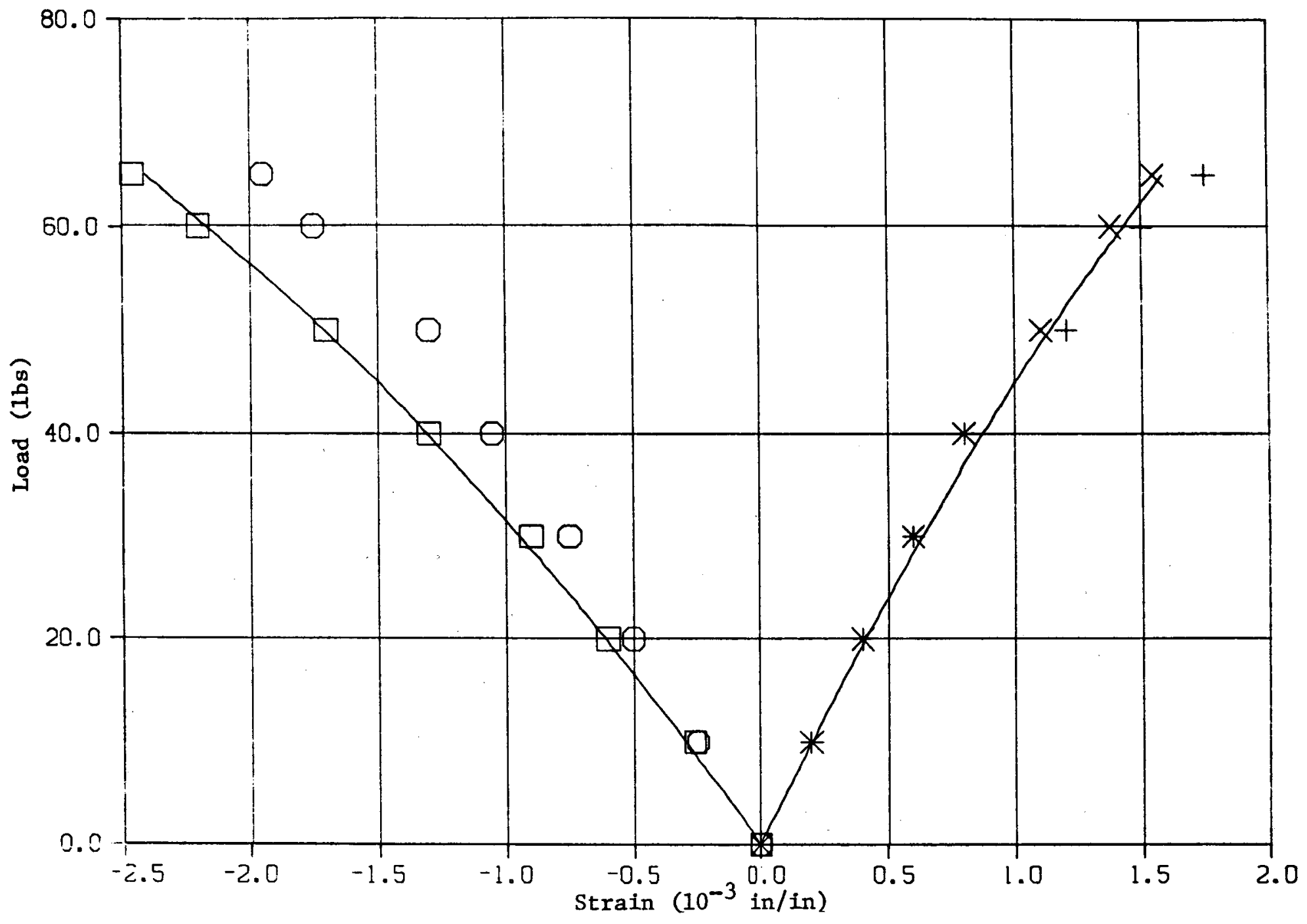

Figure 11. Comparison of strain measurements at location B ( $\square$ and $\bigcirc$ ) and C ( + and $\mathrm{X}$ ) with predictions for graphite ring of 2.2 inches inside and 2.75 inches outside diameters under diametral compression. 


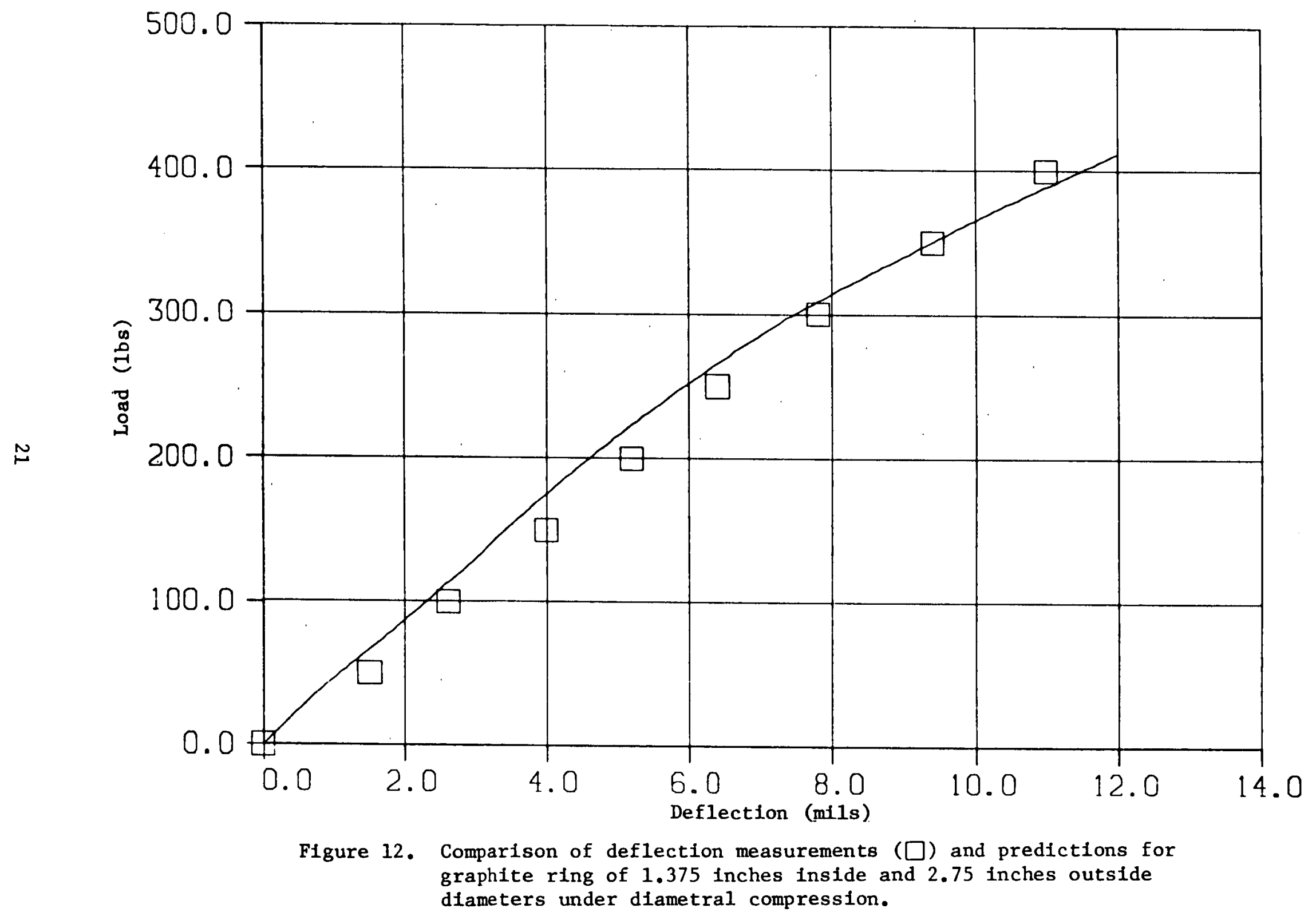




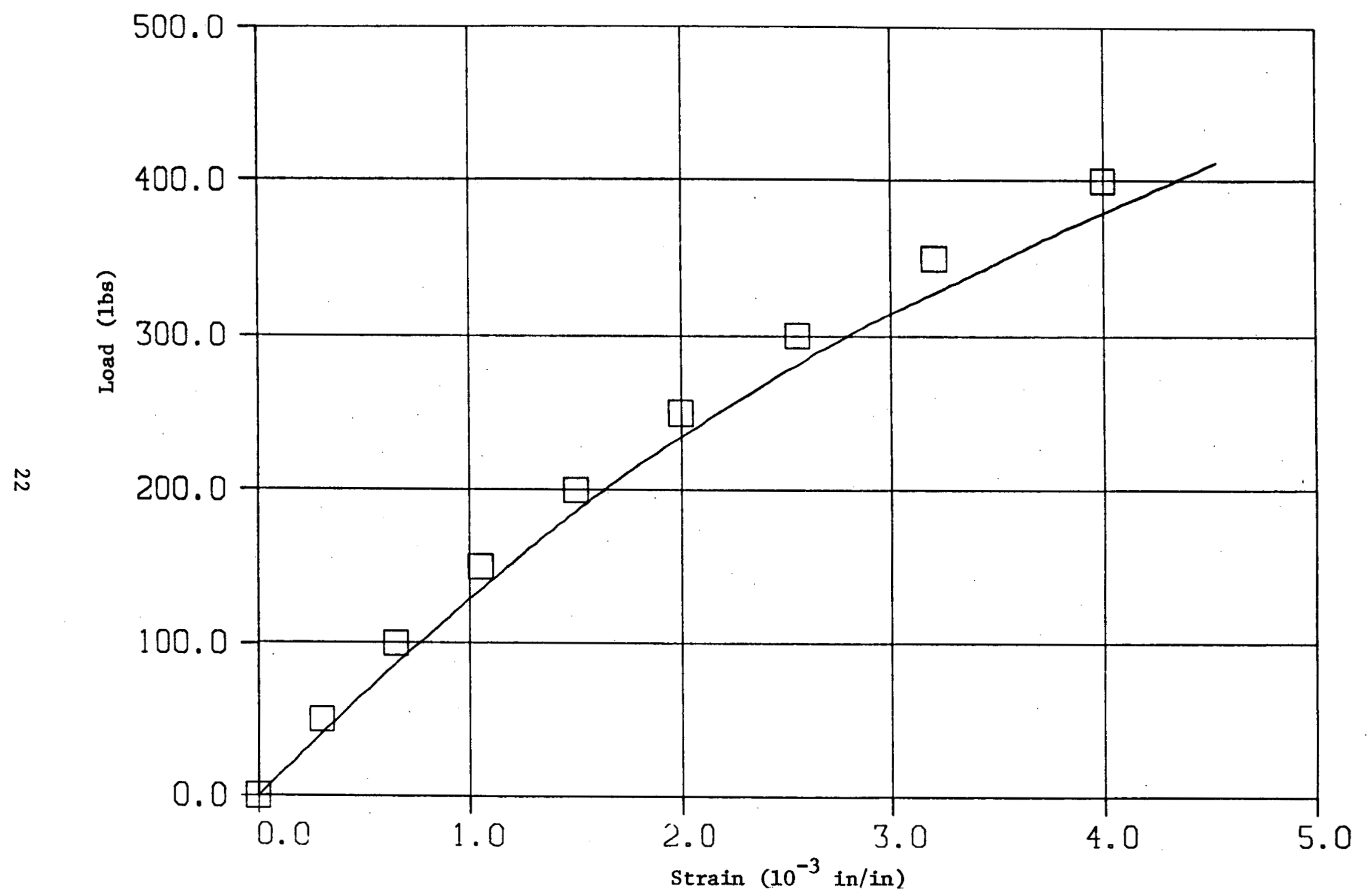

Figure 13. Comparison of strain measurements $(\square)$ at location A and predictions for graphite ring of 1.375 inches inside diameter and 2.75 inches outside diameters under diametral compression. 


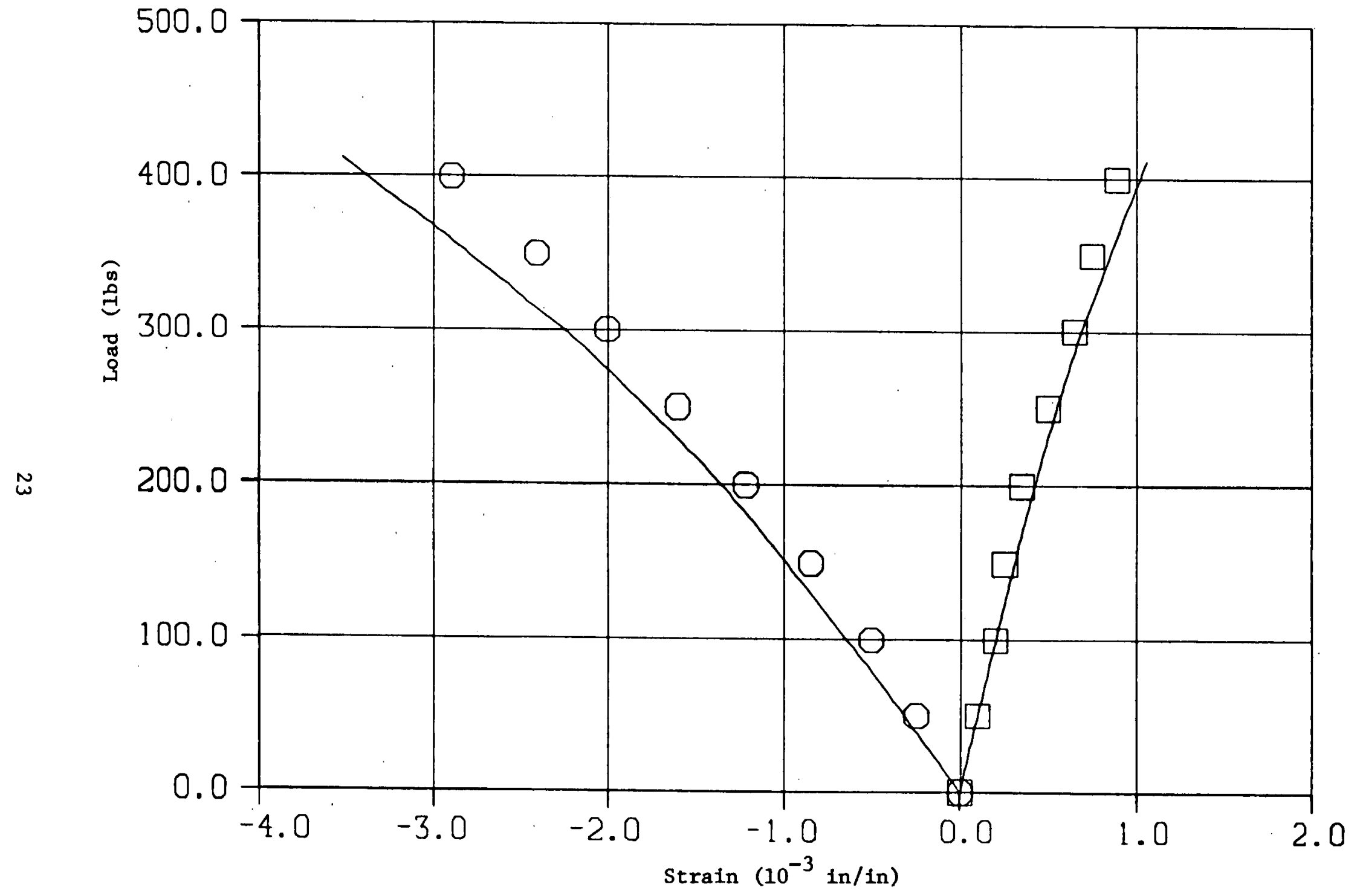

Figure 14. Comparison of strain measurements at location $B(O)$ and $C(\square)$ with predictions for graphite ring of 1.375 inches inside and 2.75 inches outside diameters under diametral compression. 
Table I

Comparison of Predictions and Measurements for 4-Point Bend and Diametral Tests

\begin{tabular}{|c|c|c|c|c|c|c|c|}
\hline \multirow{2}{*}{ Specimen } & \multicolumn{3}{|c|}{ Measured } & \multicolumn{3}{|c|}{ Present Theory } & \multirow{2}{*}{$\begin{array}{c}\begin{array}{c}\text { Linear } \\
\text { Elastic } \\
\text { Theory }\end{array} \\
\begin{array}{c}\text { Max Tensile } \\
\text { Stress } \\
\text { ps1 }\end{array}\end{array}$} \\
\hline & $\begin{array}{l}\text { Failure } \\
\text { Load } \\
\text { lbs }\end{array}$ & $\begin{array}{l}\text { Deflection } \\
\text { mils }\end{array}$ & $\begin{array}{c}\text { Strain } \\
\text { at } \mathrm{A} \\
\%\end{array}$ & $\begin{array}{l}\text { Max Tensile } \\
\text { Stress } \\
\text { psi }\end{array}$ & $\begin{array}{c}\text { Deflection } \\
\text { mils }\end{array}$ & $\begin{array}{c}\text { Strain } \\
\text { at } A \\
\%\end{array}$ & \\
\hline $\begin{array}{l}\text { 4-Point } \\
\text { Bend }\end{array}$ & 32.9 & 16.1 & 0.35 & 2163 & 15.3 & 0.44 & 2654 \\
\hline $\begin{array}{l}\text { Diametral } \\
\text { Compression } \\
d_{i}^{*}=2.2^{\prime \prime} \\
\end{array}$ & 64.2 & 26.3 & 0.45 & 2167 & 20.0 & 0.45 & 2745 \\
\hline $\begin{array}{l}\text { Diametral } \\
\text { Compression } \\
d_{1}=1.375^{\prime \prime}\end{array}$ & 434.7 & 12.8 & 0.45 & 2219 & 12.6 & 0.48 & 2725 \\
\hline $\begin{array}{l}\text { Diametra1 } \\
\text { Compression } \\
d_{1}=0.5^{\prime \prime}\end{array}$ & 1633.0 & 36.0 & 0.68 & 2715 & 36.0 & 0.82 & 3642 \\
\hline $\begin{array}{l}\text { Diametral } \\
\text { Compression } \\
d_{i}=2.2^{" 1} \\
\text { Without Strain Gage }\end{array}$ & 55.0 & 22.0 & - & 1845 & 19.3 & 0.43 & 2175 \\
\hline
\end{tabular}

$* d_{i}=$ inside diameter of ring specimen. 


\section{CONCLUSION}

The present study indicates that a modified classical plasticity theory can be used to predict the response of graphite with reasonable accuracy. This simply confirms the result in Ref. [5]. The maximum principal stress failure criterion appears to be consistent for the three cases studied. It may require more analyses as well as careful data measurement to answer the question whether classical theory is indeed applicable to graphite [16]. This theory certainly offers an attractive alternative to linear elastic theory in design analyses for graphite components. 


\section{ACKNOWLEDGEMENTS}

The author acknowledges the support of $R$. Vollman and the discussion of R. Price and F. Ho in performing this work. 
1. Greenstreet, W. L., Smlth, J. E., Yahr, Y. L., and Valanchovic, R. S., "The Mechanical Behavior of Artificial Graphites as Portrayed by Uniaxial Tests," Carbon, Vol.8, pp. 649-668, 1970.

2. Weng, T., "Stress-Strain Properties of Grade ATJ Graphite Under Combined Stresses," Proceedings of the Conf. on Continuum Aspects of Graphite Design, November 9-12, 1970, Gatlinburg, Tennessee, CONF-701105, NTIS, U.S. Dept. of Commerce.

3. Jones, R. M., and Nelson, D. A. R., Jr., "A New Material Model for the Nonlinear Biaxial Behavior of ATJ-S Graphite," J. Composite Materials, Vol. 9, January 1975.

4. Batdoft, S. B., "A Polyaxial Stress-Strain Law for ATJS Graphite," J. of Am. Ceramic Soc. Vo1. 59, No. 7-8, 1976, pp. 308-312.

5. Greenstreet, W. L., Yahr, G. and Valachovic, R. S., "The Behavior of Graphite Under Biaxial Tension," Carbon, Vo1. 11, 1973.

6. Greenstreet, W. L. and A. Phillips, "A Theory of an Elastic-Plastic Continuum with Special Emphasis to Artificlal Graphite," Acta Mechanics Vo1. 16, 1973, Pp. 143-156.

7. Chang, T. Y., Reich, M. and Suzuk1, H., "Nonlinear Response of Graphite Structures," Proc. of the Japan-U.S. Seminar on HTGR Safety Technology, Brookhaven National Laboratory, 1977.

8. Green, A. E., and Naghdi, P. M., "A General Theory of an ElasticPlastic Continuum," Archive for Mechanics and Analysis, Vol. 18, 1965, pp. 251-281.

9. Prager, W. "A New Method of Analyzing Stress and Strain in Work-Hardening Plastic Solids," J. App1. Mech., Vo1. 23, 1956, p. 493.

10. Jenkins, G. M., "Analysis of the Stress-Strain Relationships in Reactor Grade Graphite," Brit. J. App1. Phys., Vol. 13, 1962, pp. 30-32.

11. Tzung, F. K., "GTEPC-2D, A Computer Program for Two-Dimensional Graphite Thermal-Elastic-Plastic-Creep Analysis, User's Manual," General Atomic Report GA-A13532, January 1976. 
12. Zienkiewicz, C. C., S. Valliappan, and I. P. King, "Elasto-Plastic Solutions of Engineering Problems, 'Initial Stress,' Finite Element Approach," Int. J. for Numerical Methods in Engineering, Vo1. 1, 1969, pp. 75-100.

13. Price, R. and Sevier, L., "A Comparison of Analytical and Experimental Results for Four Point Bend and Diametral Ring Compression Tests of H-327 Graphite," unpublished data, General Atomic Company, August 1978.

14. Tzung, F. K., "Study of Fuel Block Collision in HTGR Core," 4th Int'1 Conf. on Structural Mechanics in Reactor Technology, $\mathrm{K} 7 / 5$, San Francisco, 1977.

15. Price, R., private communication.

16. Brocklehurst, J. E. and M. I. Darby, "Concerning the Fracture of Graphite under Different Test Conditions," Materia1 Science and Engineering, Vo1. 16, 1974, pp. 91-106. 